\title{
MELDTE DØDSFALL
}

Helge K. Korneliussen 28.8. 1941-16.5. 2015

Kjell E. Nordlie 10.2. 1938-11.5. 2015

Oddvin Mørch Rogstad 28.7. 1947-18.4. 2015

Lars Fridthjof Moe 11.11. 1932-13.4. 2015

Per Jonas Øglænd 3.7. 1954-6.4. 2015

Erik Segaard 19.2. 1938-23.3. 2015

Johannes Smehaug 18.11. 1935-9.3. 2015

Antoni Wegrzyn 7.4. 1949-9.3. 2015

Bjørn Hedberg 30.3. 1946-28.2. 2015

Petter Østhus 22.4. 1953-18.2. 2015

Johannes Høie 1.12. 1956-13.2. 2015

Wilhelm H.C. Swensen 11.11. 1923-8.2. 2015

John Harald Skjøtø 10.12. 1935-4.6. 2015

Øivind Chr. Hvalby 15.5. 1953-23.5. 2015

Tine von Hanno 21.2. 1944-22.5. 2015

Øyvind Reksten 20.9. 1958-15.5. 2015

Inge Arnljot Tøien 22.7. 1929-25.2. 2015

Jørn-Tage Angvik 9.6. 1954-4.6. 2015

Ståle Haug 2.10. 1946-3.6. 2015

Nils Andreas Hunstad 31.10. 1930-27.5. 2015

Per Eirik Hæreid 24.5. 1956-27.5. 2015

Geir Egil Skjæraasen 4.1. 1923-12.12. 2014 